\title{
An Unhealthy, Obesogenic Lifestyle: A Case Study of Urban Primary School Children in Kwekwe, Zimbabwe
}

\author{
Dube Adiele $^{1, ~ *}$, Gundani Patrick Morgan ${ }^{2}$, Lunga Mande Carolyne ${ }^{3}$ \\ ${ }^{1}$ Department of Emergency Medical Care, Emergency Medical Ambulances Services, Kwekwe, Zimbabwe \\ ${ }^{2}$ Department of Sports Science and Coaching, Faculty of Applied Sciences, National University of Science and Technology, Bulawayo, \\ Zimbabwe \\ ${ }^{3}$ Department of Journalism and Media Studies, Faculty of Communication and Information Sciences, National University of Science and \\ Technology, Bulawayo, Zimbabwe
}

Email address:

adieledube@yahoo.com (D. Adiele)

${ }^{*}$ Corresponding author

To cite this article:

Dube Adiele, Gundani Patrick Morgan, Lunga Mande Carolyne. An Unhealthy, Obesogenic Lifestyle: A Case Study of Urban Primary School Children in Kwekwe, Zimbabwe. Science Journal of Public Health. Vol. 6, No. 2, 2018, pp. 35-42. doi: 10.11648/j.sjph.20180602.11

Received: January 16, 2017; Accepted: April 1, 2017; Published: January 17, 2018

\begin{abstract}
Objectives: To determine the socio-demographic and anthropometric characteristics of 9-11 years old children in relation to their tuck-shop purchasing habits. Methods: A cross-sectional research design using a pre-designed questionnaire was administered to Grades 3, $4 \& 5$ children and two tuck shop managers from group A schools. Weight and height were measured through standardized techniques and body mass index (BMI) was calculated. BMI was interpreted in relation to tuck-shop purchasing habits. The distributions of blood pressure by anthropometric characteristics were examined. Mean, standard deviation, Pearson's correlation coefficient and Chi square were used for statistical analysis using SPSS 20.0 software. Results: The sample comprised $53.01 \%$ females $(\mathrm{n}=334)$ and $46.98 \%$ males $(\mathrm{n}=296)$. The children's mean age was $9.8( \pm 0.44)$ years, with a mean body mass index (BMI) of $20.5( \pm 4.6) \mathrm{kg} / \mathrm{m}^{2}$ for girls and $19.7( \pm 4.9) \mathrm{kg} / \mathrm{m}^{2}$ for boys. Basing on BMI, $27 \%$ of the male subjects were predominantly overweight, whereas $28.4 \%$ of the female subjects were more prone to obesity. Out of the total population, $26.4 \%$ of the children reported that they frequently purchase from the tuckshop. There was a positive significant $(p<0.013)$ association existed between the BMI and the frequency of purchasing from the tuckshop. Purchasing times continued to be unassociated to perceived health status despite that items purchased and age were inversely associated students' food consumption (Item purchased: $\mathrm{OR}=1.12, \mathrm{CI}=1.03-1.13, \mathrm{p}=0.001$; Age $\mathrm{OR}=1.06, \mathrm{CI}=1.02-$ $1.12, \mathrm{p}=0.001)$ An average of USD $\$ 0.50$ or ZAR5 is spent by children at the tuck-shop on a daily basis. Conclusion: Poor tuck-shop purchasing practices by primary school children contribute to the development of childhood overweight and obesity. Despite, schools covering nutrition in their educational curriculum, their tuck shops stocked poor nutritional quality items which were used to generate revenue/profit. Therefore, school management has a vital role in imposing restrictions over trading of unhealthy items to school children. Also, there is need to improve the nutrition educational curriculum in lower grade levels to ensure that they adopt healthier purchasing practices.
\end{abstract}

Keywords: Overweight, Childhood Obesity, Body Mass Index, Group a Schools, Tuck-Shop Purchasing Practices

\section{Introduction}

The levels of overweight and obesity among children and adolescents in Zimbabwe are increasing [1]. Children who originate from households across the living standards measure segments, may be at risk of becoming either underweight or overweight and obese [2, 3, 4]. A recent study comparing data from the World Health Organisation (WHO) and World Bank (WB) in 2010 and 2013 indicates upward trend in the level of overweight and obesity among Zimbabwean children and adolescents [5]. The study revealed that in 2002, males and females aged 5-14 years who were overweight were $15.3 \%$ and $15.4 \%$ respectively. Among the children aged 5-9 years, the rates of overweight 
in males increased from $17.0 \%$ in 2010 to $19.0 \%$ in 2013 while; among females, overweight rates maintained $11.0 \%$ in 2010 and 2013. The study also revealed that among adolescents; the males overweight rates increased from $4.3 \%$ in 2010 to $4.4 \%$ in 2013 ; among females, overweight rates were maintained at $19.0 \%$ in 2010 and 2013 . Overweight and obesity may be independently, or may, interact, hence contributing to elevated blood pressure or hypertension among children and adolescents [6].

Increasing levels of overweight and obesity among is an enormous challenge faced by children and adolescents today. It is postulated that overweight children and adolescents have a more than twofold increased risk of developing prehypertension and more than fourfold increased risk of developing hypertension compared to those with normal weight [7]. The International Association for the Study of Obesity (IASO) estimates that more than 200 million children who attend school are overweight [8].

Many children who are living in developing countries are also prone to overweight and obesity [9]. Because of this, the effects of the current childhood obesity continue to manifest through adulthood and require lifelong medical treatment [10]. Zimbabwe is among developing countries undergoing socioeconomic transformation, increased urbanization [11, 12]. The patronage of fast-foods restaurants coupled with attendant lifestyle habits promote sedentariness and possible determinants of overweight and obesity among children and adolescents in the country. In developing countries, undernutrition and over-nutrition is prevalent and occurs at the simultaneously in the population [4]. IASO reports that the generation of obese children will have a shorter lifespan than their parents and developing countries may not be able to afford the extensive healthcare expense [1, 10, 11]. Therefore, it is important to understand the prevalence of childhood overweight and obesity so that measures and strategies can be implemented to mitigate these risks and optimize health outcomes.

Most peri-urban and urban schools make food and beverage items available in the school tuck shop for their students to purchase, as a result, could encourage development of childhood overweight and obesity [10]. The patronage of fast-foods, availability of unhealthy, energydense food choices may greatly influence children's decision to make unhealthy purchases. Zimbabwean schools are measured by academic pass rate which are published, consequently children could be occupied with work at the expense of play and sports. Excess energy intake of food and beverages could then result in gaining weight which could ultimately lead to childhood overweight and obesity [13, 14]. Therefore, it is important to determine the food and beverages that are available for consumption at these schools [15] and minimise disruptions of break and lunch times to enable physical activity through patterned play of children.

It is imperative that children are introduced to money, food choices, food quantities and portions they want to consume, purchasing decisions and eating behaviour patterns at a very early age $[16,17]$. In Zimbabwe, it is formalised that children go to school at early age of 4- 5years, while in some cases they start preschool with three years at nursery schools. With such a very long period of exposure to a parent free environment, children solely make their decision on what to purchase, consume and at what time. In 2008 -9, Zimbabwe was hit by severe drought which resulted in socio-economic depression. During this period, there were scarce food products, which forced many people to buy and consuming available food without considering nutritional guides. Introduction of multi-currencies in 2009 turned Zimbabwean economy for the better. Unhealthy food products increased in the market, leading to increased poor purchasing decisions among ages [16]. The purpose of this study was to determine whether the tuck shop purchasing habits of primary school children contribute towards the development of childhood overweight and obesity.

\section{Methods}

\subsection{Sample Size and Sampling}

The sample size included a total of 680 school children aged 9-11 years and 2 tuckshop attendants residing in Kwekwe were purposively selected. From this sample, 630 (296 boys and 334 girls) children voluntarily agreed to participate in this study. The data were collected from January-March 2015. Two group A primary schools with tuckshops containing a variety of healthy and unhealthy tuck shop items available for purchase were identified.

\subsection{Ethical Considerations}

Ethical approval for this study was obtained from the National University of Science and Technology (NUST) Ethics committee. Permission to use the schools was obtained from the Ministry of Primary and Secondary Education, Midlands Province and School Development Association (SDA). Informed consent was obtained from each of the study participants from their parents or guardians. Only children with both written assent and consent were used as subjects in this study. Children in grades $3-5$ who are aged 9-11years were chosen on the basis that they are able to interpret questions and concentrate for a minimum of 30 minutes $[18,19]$. All entry forms were kept by the Principal Investigator and completed questionnaires were only viewed by approved study personnel.

\subsection{Data Collection}

A three-part questionnaire was administered to Grade 4 \& 5 children. An adapted predesigned questionnaire from Wailes (2011) was used, broken down into sections; -Section A: socio-demographic information and anthropometric data (grade, age, weight and height); -Section B: tuck-shop purchasing practices with a 3-point Likert scale, including the options "agree", "neutral", "disagree". Grades 3, 4 \& 5 primary school teachers were consulted to ensure that the language is appropriate for interpretation for Grade 3, 4 \& 5 children. Administration of the questionnaire was done by 
Grade 3, 4 \& 5 class teachers, while three final-year degree students in Sports Science and Coaching assisted in obtaining the anthropometric measurements. Training sessions prior to the tests were conducted with the teachers and assistant to ensure that the data were collected in a standardised, reliable manner. Tuckshop weekly sales and order quantities were recorded and compared to data gathered from the completed questionnaires.

\subsection{Data Analysis}

The SPSS version 16.0 statistical software was used for data entry and statistical analysis. Pearson correlation analysis and Chi-square tests were performed. $P$-value $<0.05$ was regarded as statically significant.

\section{Results}

\subsection{Anthropometric Characteristics}

The sample comprised 53.01\% females $(\mathrm{n}=334)$ and $46.98 \%$ males $(\mathrm{n}=296)$. Table 1 below shows anthropometric characteristics of the subject group.

Table 1. Mean and standard deviation (sd) for anthropometric measurements of the study population.

\begin{tabular}{lllll}
\hline \multirow{2}{*}{ Variable } & Boys $=\mathbf{2 9 6}$ & Girls $=\mathbf{3 3 4}$ & Combined & \multirow{2}{*}{ P-value } \\
\cline { 2 - 4 } & Mean $\pm \mathbf{s d}$ & Mean $\pm \mathbf{s d}$ & Mean $\pm \mathbf{s d}$ & \\
\hline Age $($ years $)$ & $9.9 \pm 0.48$ & $9.7 \pm 0.40$ & $9.8 \pm 0.44$ & 0.302 \\
Body mass $(\mathrm{kg})$ & $39.5 \pm 13.3$ & $40.3 \pm 13.1$ & $39.9 \pm 13.2$ & 0.545 \\
Height $(\mathrm{cm})$ & $139.6 \pm 5.2$ & $140.3 \pm 5.8$ & $139.7 \pm 5.6$ & 0.837 \\
BMI $\left(\mathrm{kg} / \mathrm{m}^{2}\right)$ & $19.7 \pm 4.9$ & $20.5 \pm 4.6$ & $20.1 \pm 4.7$ & 0.431 \\
\hline
\end{tabular}

The children's mean age was $9.8( \pm 0.44)$ years. The mean body mass index (BMI) for girls was $20.5( \pm 4.6) \mathrm{kg} / \mathrm{m}^{2}$ while for boys was $19.7( \pm 4.9) \mathrm{kg} / \mathrm{m}^{2}$. An analysis of the results of the variables in the above table 1 (age, body mass, height and BMI) revealed that neither of the gender groups was positively significant.

Table 2. Classification of children based on BMI $\left(\mathrm{kg} / \mathrm{m}^{2}\right)$.

\begin{tabular}{lllllll}
\hline \multirow{2}{*}{ Variable } & \multicolumn{2}{c}{ Boys $=\mathbf{2 9 6}$} & \multicolumn{2}{c}{ Girls $=\mathbf{3 3 4}$} & \multicolumn{2}{c}{ Total $=\mathbf{6 3 0}$} \\
\cline { 2 - 7 } & $\mathbf{n}$ & $\mathbf{\%}$ & $\mathbf{n}$ & $\mathbf{\%}$ & $\mathbf{n}$ & $\mathbf{\%}$ \\
\hline Normal & 146 & 49.3 & 161 & 48.2 & 300 & 47.6 \\
Overweight & 80 & 27 & 78 & 23.4 & 158 & 25.1 \\
Obese & 70 & 23.6 & 95 & 28.4 & 165 & 26.2 \\
\hline
\end{tabular}

Table 2 above showed BMI results of boys and girls categorized as normal, overweight or obese based on World Health Organization (WHO) norms [20]. For overweight, males and females were $27 \%$ and $24.5 \%$ respectively, whilst an obesity percentage for males was 23.6 and females was $28.4 \%$.

\section{Tuck-shop operations}

The school tuck shops in this sample opened from early morning when school starts at 0745 hours until dismissal times at 1600 hours. Of the days' sales, high sales in the tuck shop were recorded during break and lunch times (52.3\% and $40.8 \%$ ) respectively. All the school attendants indicated that they placed orders once every fortnight.

\subsection{Tuck-Shop Purchasing Practices}

From the population of 630 children, $94.6 \%$ reported that they were buying from their school tuck shop while; $26.4 \%$ of the children reported that they frequently purchase from the tuckshop at least twice per day on an average of 4 days per week. Within this group it was found that there was strong significant $(p<0.013)$ association between the BMI and the frequency of purchasing from the tuck shop. Half of the population indicated that they visited and used the tuck shop at least twice a week, whilst $23.6 \%$ indicated that they only use that tuck shop at least once per week. More than half of the boys and girls who frequently purchased tuck shop items were overweight and $9.8 \%$ were obese.

On a daily basis, an average USD $\$ 0.50$ or R5 is spent by children at the tuck-shop. Those who frequently purchased from the tuck shop spent slightly more on Fridays when they were given a maximum amount of a USD $\$ 1.00$ by their parents. Children $(55.6 \%)$ indicated that their main source of tuck shop spending money was the parents or guardians, $41.7 \%$ from parents' and learner's own pocket money combined and $2.7 \%$ from the learner's pocket money. Children from Grade $3 \& 5$ purchased multiple items during break time than what the Grade 4 did during lunch time. It was noted that children's BMI, bringing lunch from home, frequency of purchases, amount spent daily, break time or lunch time purchases were not statistically correlated $(\mathrm{p}=$ $0.061)$.

Table 3. Trends of most popular purchased tuck shop items.

\begin{tabular}{lllllll}
\hline \multirow{2}{*}{ Description } & \multicolumn{3}{c}{ Break time } & \multicolumn{2}{c}{ Lunch time } & \multicolumn{2}{c}{ Dismissal time } \\
\cline { 2 - 7 } & $\mathbf{n}$ & $\mathbf{\%}$ & $\mathbf{n}$ & $\mathbf{\%}$ & $\mathbf{n}$ & $\mathbf{\%}$ \\
\hline Beverages & & & & & & \\
Carbonated & 96 & 15.2 & 80 & 12.7 & 12 & 1.9 \\
Fruit blend & 64 & 10.2 & 56 & 8.9 & 5 & 0.8 \\
Freezits & 145 & 23 & 328 & 52.1 & 98 & 15.6 \\
Sweets and chocolates & & & & & & \\
Loose sweets & 197 & 31.3 & 256 & 40.6 & 90 & 14.3 \\
Packet of sweets & 100 & 15.9 & 89 & 14.1 & 50 & 7.9 \\
Chocolate & 59 & 9.3 & 72 & 11.4 & 84 & 13.3 \\
Choco beans & 205 & 32.5 & 213 & 33.8 & 100 & 15.9 \\
Snack or lunch item & & & & & & \\
"Unhealthy” & & & & & & \\
Samoosa & 94 & 14.9 & 123 & 19.5 & - & - \\
Pies & 213 & 33.8 & 140 & 22.2 & - & - \\
Pop corn & 105 & 16.7 & 89 & 14.1 & 96 & 15.2 \\
Hot chips & 207 & 32.9 & 259 & 41.1 & 89 & 14.1 \\
Hot dog & 180 & 28.6 & 156 & 24.8 & 93 & 14.8 \\
Nibble nakes & 45 & 71.4 & 34 & 5.4 & - & - \\
Cup cakes & 30 & 4.8 & 12 & 1.9 & - & - \\
"Healthy” & & & & & & \\
Banana & 114 & 18.1 & 34 & 5.4 & 14 & 2.2 \\
Yoghurt & 109 & 17.3 & 58 & 9.2 & 9 & 1.4 \\
Loose biscuits & 89 & 14.1 & 22 & 3.4 & - & - \\
\hline & & & & & &
\end{tabular}

Table 3 shows that highest percentages were for pies (33.8\%) during break time, hot chips (41.1\%) during lunch time and pop corns $(15.2 \%)$ at dismissal time, whilst for 
'healthy' food, banana (18.1\%), yoghurt (9.2\%) and banana (2.2\%) respectively. Purchasing habits of items from the tuckshop were not statistically significant on the items they consume $\left(\chi^{2}=51.000, \mathrm{df}=3 \mathrm{p}=0.354\right)$.

Table 4. Comparison of consumption of healthy and unhealthy food stuffs bought from the tuckshop by students.

\begin{tabular}{lll}
\hline \multicolumn{2}{l}{ Lunch time food stuff for consumptiona } \\
\hline \multicolumn{2}{l}{ Turkey HSD } \\
\hline Class of item purchased & $\mathbf{N}$ & Subset for alpha $=\mathbf{0 . 0 5}$ \\
\cline { 3 - 3 } & & $\mathbf{1}$ \\
\hline healthy & 186 & 38.00 \\
unhealthy & 427 & 116.14 \\
Sig. & & 330 \\
\hline
\end{tabular}

a. Uses Harmonic Mean Sample Size $=3.775$. Means for groups in homogeneous subsets are displayed.

Results from table 4 above, showed children's purchasing habits during lunch time on 'unhealthy' food $(n=427)$ and 'healthy' food $(n=186)$ during lunch time. There was no statistical significance on lunch time consumed food products $(\mathrm{p}=0.330)$.

Table 5. Correlation coefficient among break, lunch and dismissal time.

\begin{tabular}{llll}
\hline $\begin{array}{l}\text { Opening } \\
\text { times }\end{array}$ & $\begin{array}{l}\text { Purchased items } \\
\text { for Break }\end{array}$ & $\begin{array}{l}\text { Purchased items } \\
\text { for Lunch }\end{array}$ & $\begin{array}{l}\text { Purchased items } \\
\text { for Dismissal }\end{array}$ \\
\hline Break & 1 & $0.763^{* *}$ & $0.529^{*}$ \\
Lunch & $0.763^{* *}$ & 1 & $0.712^{* *}$ \\
Dismissal & $0.529^{*}$ & $0.712^{* *}$ & 1 \\
\hline
\end{tabular}

**. Correlation is significant at the 0.01 level. *. Correlation is significant at the 0.05 level

Correlation coefficients from table 5 above indicate that there exists a statistically significant correlation of items purchased and consumed $(\mathrm{p}<0.01)$ between break time and dismissal time (0.529), break time and lunch (0.763), lunch and dismissal time (0.712) with significance $\mathrm{p}<0.05$. Considering all the items at each time they did not show any statistically significant correlation among their quantity and students' consumption. There were significantly greater purchases of unhealthy food stuffs daily compared to other tuckshop items.

Table 6. Adjusted logistic regression between purchasing habits and study variables.

\begin{tabular}{lllll}
\hline Variable & $\begin{array}{l}\text { Beta } \\
\text { coefficient }\end{array}$ & Odds ratio & 95\% CI & P value \\
\hline $\begin{array}{l}\text { Age (yrs) } \\
\text { Gender }\end{array}$ & 0.05 & 1.06 & $1.02-1.12$ & $0.001^{* *}$ \\
$\begin{array}{l}\text { Female \& Male } \\
\text { Item purchased }\end{array}$ & -1.08 & 0.36 & $0.07-1.13$ & $0.183^{*}$ \\
$\begin{array}{l}\text { Healthy } \\
\text { Unhealthy }\end{array}$ & -1.04 & 0.45 & $0.08-1.14$ & 0.523 \\
Body Mass Index (BMI) & -0.09 & 1.12 & $1.03-1.13$ & $0.001^{* *}$ \\
Purchasing time & 0 & 0.43 & $0.05-1.04$ & $0.013^{*}$ \\
\hline
\end{tabular}

$* *$ Correlation is significant at the 0.01 level (2-tailed). *Correlation is significant at the 0.05 level (1-tailed)

Adjusted logistic regression model showed that after controlling the covariates; items purchased and age were inversely associated students' food consumption (Item purchased: $\mathrm{OR}=1.12, \mathrm{CI}=1.03-1.13, \mathrm{p}=0.001$; Age: $\mathrm{OR}=$ $1.06, \mathrm{CI}=1.02-1.12, \mathrm{p}=0.001)$. The model indicated that after regulation for prospective confounders (gender, items purchased and BMI) in the model, purchasing times continued to be unassociated to perceived health status (classified BMI-table 2).

Reasons for children to purchases from the school tuck shop

Grades 3, 4 \& 5 children indicated that they were purchasing from the tuckshop due to the following reasons; the items purchased were their favourite food $(60.3 \%)$, choice food items help to keep their body healthy (57.8\%). The children indicated that their parents/guardians or people who looked after them did not prescribe any food item to be purchased and consumed at school (56.5\%), while influence from their friends had a great impact on items they purchase from the tuckshop (54\%).

\section{Discussion}

The study found that from a sample of 630 children, slightly more than half $(51.3 \%)$ were overweight or obese. The obese population exceeded overweight by $1.1 \%$. Considering BMI, girls (28.4\%) were more prone to obese, compared to their male counterparts with $23.6 \%$. Statistics from the tuckshop indicated that girl children frequently purchase than boys. Of the $94.6 \%$ reported buying from their school tuck shop, $26.4 \%$ children reported to frequently purchase from the tuck shop least twice at an average of 4 days per week. $68 \%$ of both boys and girls, who frequently used the tuckshop for at least twice per day, had BMIs above 'healthy' category. Those school children who are frequent customers with at least two or three visits to the tuck shop per week, that make poor food and beverage choices, may be at risk of becoming overweight $[21,22,36]$. These findings suggested that children who frequently purchase from the school tuckshop may be prone to overweight and obesity.

Armstrong et al (2006) investigated 10195 learners from well-resourced schools aged 6-13 years from mixed socioeconomic levels in 2001 and 2004, and reported that overweight was $10.9 \%$ and $2.4 \%$ obesity among males, $17.5 \%$ overweight and $4.8 \%$ obesity among females [11]. Wiles et al (2013), found that tuck-shop purchasing practices of 311 Grade 4 learners in Pietermaritzburg and childhood overweight and obesity revealed that $26.7 \%$ of the learners were overweight and $27.3 \%$ obese. Comparing with Wiles et al (2013) [22] report, this study found that there were slightly lower levels of overweight and obesity in childhood rating at $25.1 \%$ and $26.2 \%$ respectively.

Eighty-six percent of the sampled group brought food from home every day to eat at school. $3 \%$ of the children eat the food on their way to school. Despite having brought food to school, many children indicated that they purchase from the tuck shop to supplement what they had brought from home. More than $60 \%$ of the children were most likely to purchase items during the first and second break because the school 
tuckshops sold favorite items which they thought they can make their bodies healthy compared to what they had consumed early in the morning at home and those items packed for them to school. Comparing with other researches in the same Southern and Eastern African regions, high percentages ( $85 \%$ in the Soweto- Johannesburg Birth to Twenty cohort and $69 \%$ in a Cape Town respectively) of adolescents bought from tuck shops [24, 25], Kenya were $25 \%$ for children between $9-10$ years in 2013 [38], Australia had $31 \%$ for children aged between $4-13$ years [39] and Canada was $32.9 \%$ among girls [40]. For primary schools it was found to be different in those children who purchased from the tuck shop every day from Pietermaritzburg, South Africa was a lower percentage of $12 \%$ [22] than a $26.4 \%$ for those in this study.

Grade 3, 4 \& 5 children who frequently purchase items from the tuckshop had higher BMIs compared to their counterparts, who did not. Templeton (2005) [24] found that the availability of unhealthy foods in school cafeterias, vending machines and tuck shops promote unhealthy food choices. Therefore, based on this argument it has been suggested that school tuckshops may be playing a vital role in contributing in the development of overweight and obesity childhood $[2,22]$. This may have resulted from children's nutrition knowledge levels influencing the impact of food and beverage purchases. Also, school tuckshops may have been stocking more unhealthy food products; that were energy dense and high in fat, indirectly influencing purchasing and consumption.

Our results suggest that parents played an important role by supporting their children with lunchboxes and extra money to spend at the tuckshop. School management has influential responsibility in preventing childhood overweight and obesity through the items that they choose to make available for sale and or consumption [25]. Despite that, many children bring lunch boxes of food to school, while schools do not discourage children from carrying extra money for purchasing supplement food from tuckshop. The education curriculum emphasizes on nutrition and physical activity, drawing focus on procedures that lead to positive health outcomes, rather than managing the consequences of unhealthy behaviours [26, 32]. However, the school management were reluctant to take an action may be because the food and beverages sold at school for profit-making. Learners should not be tasked with the 'responsibility' of contributing to the generation of school funds by purchasing unhealthy food and beverages [27].

Whilst more than $80 \%$ of the children indicated that they brought home-packed lunch to school after taking breakfast at home, they purchased food items from the tuck shop because they considered the food items to be their favorite items which they are also able to afford. It was imperative that $48.2 \%$ agreed that they like what they bring from home, however more than half were not told what to purchase as food supplements by parents/guardians. In this study, children of 9- 11 years old exercised personal choices of purchasing food items. In the early stages of childhood, a parent has the greatest influence and responsibility in encouraging children to find ways and broaden healthier food preferences when tuck-shop purchasing. 54\% agreed that their friends and media influenced their purchasing habits. As a child grows, this influence from parents/guardians is soon replaced by the media, the peers surrounding him/her as well as the quality of the nutrition education received at school [28]. School nutrition policies and tuck shop guidelines should be developed and implemented to support healthy eating habits [17, 29, 32]. Therefore, the school can be considered as an appropriate environment where one can influence knowledge about nutrition and thereby equip children with the skills necessary to maintain a healthy lifestyle [15, 20, 31].

This study showed that BMI had an inverse significant association with purchasing times, purchased food stuffs and perceived health. This finding is consistent with literature for workers with greater body mass indices perceived their health status as poorer than their counterparts with lower body mass indices [35, 41]. Major factors linked to childhood overweight and obesity include, higher sedentary behaviour, dietary behaviour such as frequency of sweets intake, lower physical activity levels $[10-12,14,38,40]$. Therefore, for overweight and obese students to improve their health and participate in school physical activity and sport programs, educators and sports coaches can benefit from students' selfrated responses to their purchasing habits, health status and items purchased at school. Moreso, self-interception by the students on health status of food they consume in and out of school environment can help them to work towards improving and find proper interventions on their health by involving themselves in physical activities and having positive attitude towards eating health food products.

Limitations of the study

The current study had the following limitations;

a) This research only considered the age of 9-11 years old

b) Self-rating, completing the questionnaire by the children could have be misinterpreted by the subjects

c) Current research focused on purchasing habit at school without consideration of attention given by parents to their children in out of school environment, such as gifts, more luxurious foods and more sedentary recreation gadgets and activities

d) Because of the cross-sectional nature of this study, information on the predictor and outcome variables were collected and analyzed at one moment in time and therefore, the direction of causality cannot be determined.

e) This cross-sectional study considered anthropometrical aspects major contributors of overweight and obesity without inclusion of hormonal, immunological, neural, metabolic and other mechanisms which are of great influence to weight regulating systems.

\section{Conclusion}

Children from Grades 3, 4 \& 5 who make frequent 
purchases from their school tuck shop have been discovered to be overweight or obese. Despite, children's knowledge of non-communicable diseases, they purchase items based on preference, affordability, peer influence and not according to its nutritional values and health status. In this regard, school tuckshops may be playing a role in promoting an early onset of childhood overweight and obesity. Since school management have an important role to play in imposing restrictions on the sale of unhealthy food and beverages; they need to implement and improve educational curriculum for healthy and quality nutrition ensuring that primary school children are able to use learnt knowledge into healthier purchasing practices.

\section{Recommendations}

Primary school education and learning is the norm and in order to support health promotion school personnel, families and community members can be involved [32, 33]. Based on the findings of this study, the following recommendations are made for successful preventative strategies of the nutritionally-regulated tuck shop purchasing habits in order to advance healthy eating practices among school children:

a) The school setting should empower and sensitise children, parents and the community through dissemination of health and nutritional knowledge

b) Restrict trading of unhealthy items at the school tuck shop. Wiles et al. (2011) also recommended that tuck shop managers should also be educated regarding the appropriate quality and quantity of ingredients used in the preparation of homemade tuck shop items

c) To call for government intervention on reduction of the mainstream media advertising of unhealthy food related products, and focus more encouraging more advertisement of healthy food stuffs.

d) Teaching of Agriculture practical lessons and having vegetable gardens at schools can promote the intake of vegetables and encourage children to taste vegetable foods [34].

e) Involving and educating parents on the promotion of a healthy lifestyle at home in order to gain their support, since they influence their children's nutrition-related perceptions and dietary behaviours

f) Encouraging parents to limit the amount of pocket money given to children to make tuck-shop purchases.

g) Promote physical activity by upgrading schools and community physical activity and sport infrastructure.

\section{Implications of Future Research}

Fast growing epidemic of obesity and other noncommunicable diseases are current issue that worries at a global level and more in a population such as children's, looking for associated factors will be the best element to prevent and be able to solve this public health problem. Longitudinal data and improved ways of disseminating information are needed in this $21^{\text {st }}$ century to create a greater awareness and an enhanced understanding about sedentary lifestyle [35] of future generations' health, relationship between purchasing/eating habits, BMI, health perception and physical activity. Health professionals should be aware of the modifiable causes of childhood obesity and to implement physical activity, exercise and nutrition management as a primary approach to intervention [33, 37]. Further longitudinal researches can compare children from urban and rural schools, national regional and patterns in underweight, overweight and obesity in the following categories; preschool children, early childhood learners, children in primary schools and adolescents from all geographical areas, ethnicities, socio-economic strata, and cultures in Zimbabwe and African countries.

\section{Conflict of Interest}

No conflict of interest is declared.

\section{Ethical Statement}

The study was approved by The National University of Science and Technology (NUST) Research Ethics Committee (2015/3740). Permission (2015/112) from the Ministry of Primary and Secondary Education was given.

\section{Acknowledgements}

The authors acknowledge the Ministry of Primary and Secondary Education, teachers and children who gave their time to participate in this study. This research was funded by a small research grant from the Global Intern Mentee Africa.

\section{References}

[1] Mufunda E and Makuyana L Obesity: A Potential Pandemic for the $21^{\text {st }}$ Century among the Youths in Zimbabwe. Journal of Diabetes Mellitus, 2016: 6; 136-145 http://dx.doi.org/10.4236/jdm.2016.62014

[2] Abrahams Z, De Villiers A, Steyn NP, et al. What's in the lunchbox? Dietary behaviour of learners from disadvantaged schools in the Western Cape, South Africa. Public Health Nutrit. 2011; 14 (10): 1752-1758.

[3] Cassim SB. Food and beverage marketing to children in South Africa: mapping the terrain. S Afr J Clin Nutr. 2010; 23 (4): 181-185.

[4] Du Toit G, Van der Merwe MT. The epidemic of childhood obesity. S Afr Med J. 2003; 93 (1): 49-50.

[5] Zimbabwe (2014) Nutrition Country Profile: Economics and Demography Child Anthropometry Adolescent and Adult Nutrition Status. www.globalnutritionreport.org

[6] Prell, H. "Promoting dietary change. Intervening in school and recognizing health messages in commercials," working paper, Faculty of Education, University of Gothenburg, Gothenburg. 2010. 7 May. 
[7] Downs SM, Farmer A, Quintanilha M, Berry TR, Mager DR, Willows ND, McCargar LJ. From paper to practice: barriers to adopting nutrition guidelines in schools. JNEB 2012; 44 (2): 114-122.

[8] International Association for the Study of Obesity [homepage on the Internet]. c2011. Available from: www.iaso.org

[9] Wang Y, Lobstein T. Worldwide trends in childhood overweight and obesity. Int J Pediatr Obes. 2006; 1 (1): 11-25.

[10] Lobstein T, Baur L, Uauy R. Obesity in children and young people: a crisis in public health. Obes Rev. 2004; 5 Suppl 1: 4104.

[11] Armstrong MEG, Lambert MI, Sharwood KA, Lambert EV. Obesity and overweight in South African primary school children: the Health of the Nation Study. S Afr Med J. 2006; 96 (5): 439-444

[12] Kruger R, Kruger HS, Macintyre UE. The determinants of overweight and obesity among 10-to- 15-year-old schoolchildren in the North West Province, South Africa-the THUSA BANA (Transitional and Health during Urbanisation of South Africans; BANA, children) study. Publ Health Nutr. 2005; 9 (3): 351-358

[13] St-Onge MP, Keller KL, Heymsfield SB. Changes in childhood food consumption patterns: a cause for concern in light of increasing body weights. Am J Clin Nutr. 2003; 78 (6): 1068-1073.

[14] Birch LL, Ventura AK. Preventing childhood obesity: what works? In J Obes (Lond). 2009; 33 Suppl 1: S74-S81.

[15] Story M. The third school nutrition dietary assessment study: findings and policy implications for improving the health of US children. J Am Diet Assoc. 2009; 109 (2 Suppl): S7-S13.

[16] Kraak V, Pelletier D. The influence of commercialism on the food purchasing behavior of children and teenage youth. Family Economics and Nutrition Review. 1998; 11: $15-24$.

[17] Gidding SS, Dennison BA, Birch LL, et al. Dietary recommendations for children and adolescents: a guide for practitioners: a consensus statement from the American Heart Association. Circulation. 2005; 112 (13): 2061-2075.

[18] Hoelscher DM, Day S, Lee ES, et al. Measuring the prevalence of overweight in Texas school children. Am J Pub Health. 2004; 94 (6): 1002-1008.

[19] DeVault N, Kennedy T, Hermann J, et al. It's all about kids: preventing overweight in elementary school children in Tulsa, OK. J Am Diet Assoc. 2009; 109 (4): 680-687.

[20] World Health Organization. Growth reference data for 5-19 years. Geneva: World Health Organization; 2011 [homepage on the Internet]. 2011. Available from: http://www.who.int/growthref/en/

[21] Finch M, Sutherland R, Harrison M, Collins C. Canteen purchasing practices of year 1-6 primary school children and association with SES and weight status. Aust N Z J Public Health. 2006; 30 (3): 247-251

[22] Wiles NL, Greeny JM, Veldman FJ Tuck-shop purchasing practices of Grade 4 learners in Pietermaritzburg and childhood overweight and obesity. S Afr J Clin Nutr 2013; 26 (1) $37-42$
[23] Feeley A, Musenge E, Pettifor JM, Norris SA. Changes in dietary habits and eating practices in adolescents living in urban South Africa: the birth to twenty cohort. Nutrition. 2012; 28 (7-8): e1-e6.

[24] Templeton S. Competitive foods increase the intake of energy and decrease the intake of certain nutrients by adolescents consuming school lunch. J Am Diet Assoc 2005; 105: 215220

[25] Temple NJ, Steyn NP, Myburgh NG, Nel JH. Food items consumed by students attending schools in different socioeconomic areas in Cape Town, South Africa. Nutrition. 2006; 22 (3): 252-258.

[26] WHO. Milestones in Health promotion: Statements from Global conferences. Geneva: World Health Organisation. [Online] 2009 [access 2015, March 27]; Available: http://www.who.int/healthpromotion/Milestones_Health_Pro motion_05022010.pdf.

[27] Dorfman L, Wallack L. Moving nutrition upstream: the case for reframing obesity. Journal of Nutrition Education and Behaviour 2007; 39: S45-S50

[28] Lissau I, Poulsen J Nutrition policy, food and drinks at school and after school care. International Journal of Obesity 2005; 29: S58-S61

[29] Vereecken C, Bobelijn K, Maes L. School food policy at primary and secondary schools in Belgium-Flanders: does it influence young people's food habits? Eur J Clin Nutr 2005; 59: $271-277$.

[30] Steyn NP, Lambert EV, Parker W, Mchiza Z, De Villiers A. A review of school nutrition interventions globally as an evidence base for the development of the Health kick programme in the Western Cape, South Africa. SAJCN 2009; 22 (3): 145-152.

[31] Kubik MY, Lytle LA, Hanan PJ, Perry CL, Story M The association of the school food environment with dietary behaviours of young adolescents. American Journal of Public Health 2003; 93: 1168-1173

[32] Wang D, Stewart D. The implementation and effectiveness of school based nutrition promotion programmes using a health promoting schools approach: a systematic review. Public Health Nutr 2012; 31: 1-19.

[33] WHO. Creating an Environment for Emotional and Social Well-Being: An Important Responsibility of a HealthPromoting and Child Friendly School. [Online] 2003 [access 2015, March 25; Available on: www.who.int/school_youth_health/media/en/sch_childfriendl y_03.pdf

[34] Ransley JK, Taylor EF, Radwan Y, Kitchen MS, Greenwood DC, Cade JE. Does nutrition education in primary schools make a difference to children's fruit and vegetable consumption? Public Health Nutr. 2010; 13 (11): 1898-1904.

[35] Sarkar S, Taylor WC, Lai D, Shegog R, Paxton RJ (2016) Perceived Health, Sedentary Time, Body Mass Index, and Breaks from Prolonged sitting in the Workplace. Int J Sports Exerc Med 2.044

[36] Physical status: the use and interpretation of anthropometry. Report of a WHO Expert Committee. World Health Organ Tech Rep Ser 1995: 854: 1-452. 
[37] The obesity prevention Source: globalization. Harvard School of Public Health [homepage on the Internet]. c2013. Available from: http://www.hsph.harvard.edu/obesity-preventionsource/obesity-causes/globalization-and-obesity/

[38] Kyallo F, Makokha A, Mwangi A. M. Overweight and obesity among public and private primary school children in Nairobi, Kenya. Health 2013: (5); 85-90

[39] Waters, E., Ashbolt, R., Gibbs, L., Booth, M., Magarey, A., Gold, L. Kai Lo, S., Gibbons, K., Green, J., O'connor, T., Garrard, J. and Swinburn, B. Double disad- vantage: The influence of ethnicity over socioeconomic position on childhood overweight and obesity: Findings from an inner urban population of primary school chil- dren. International Journal of Pediatric Obesity, 2008: 3; 196- 204. http://dx.doi.org: 10.1080/17477160802141846

[40] Veugelers, P. J. and Fitzgerald, A. L. Prevalence of and risk factors for childhood overweight and obesity. Canadian Medical Association Journal, 2005: 173; 607-613. http://dx.doi.org:: 10.1503/cmaj.050445

[41] Pék E, Mártai I, Marton J, Betlehem J Health survey of ambulance workers with a generic questionnaire (SF-36). Orv Hetil 2013: 154: 1865-1872. 